\title{
Facilitating Interaction in East Asian EFL Classrooms: Increasing Students' Willingness to Communicate
}

\author{
Scott Aubrey \\ Ritsumeikan Asia Pacific University, Japan
}

\begin{abstract}
Research has pointed to specific classroom conditions that increase EFL students' willingness to communicate in English (WTC); these include group cohesiveness, topic relevancy, and anxiety. Additionally, certain languagelearning attitudes, such as international posture and student acceptance of communicative language teaching (CLT), have been shown to affect a student's WTC. This paper will explain how, by paying close consideration to these variables, teachers in East Asian classrooms can promote their students' WTC and improve spoken interaction among their students.
\end{abstract}

Having deep linguistic knowledge is no longer a sufficient goal for EFL students; students must strive for communicative competence in English as well. Because of this, it is imperative that teachers not just provide opportunities for students to practice language skills in a communicative way - they must also instill in students certain attributes that are conducive for creating a communicative environment. Thus, one primary goal of language teachers should be to increase their students' willingness to communicate in English (WTC).

\section{Key Concepts for Discussing Communicative Classrooms in the East Asian Context}

Willingness to communicate in English. WTC, a fairly recent development in L2 instruction theory, has been described as the probability that one will engage in communication when one is free to do so (McCroskey \& Baer, 1985). For a teacher to teach English communication skills, students must possess a high WTC to be ready to participate in activities focusing on "unpredictable" uses of language forms (Littlewood, 2007, p. 247). WTC in a first language is mainly attributed to personality factors; however, WTC in L2 is considerably more complicated. Maclntyre, Clément, Dörnyei, \& Noels (1998) suggested a heuristic model that accounts for L2 WTC behavior and proposed the following as possible influences: situated antecedents, motivational propensities, affective-cognitive context, and social and individual context. Research has indicated that many other situation-specific elements partially account for L2 WTC as well; some include group cohesiveness, anxiety, and topic relevancy, all of which could be important factors when teachers attempt to construct an ideal classroom environment (Aubrey, 2010; Cao \& Philp, 2006; De Saint Léger \& Storch, 2009). By giving careful consideration to influences on WTC, teachers can manipulate classroom conditions and tap into students' latent WTC to optimize student interaction.

Language Education in Asia, 2011, 2(2), 237-245. http://dx.doi.org/10.5746/LEiA/11/V2/I2/A06/Aubrey 
Communicative Language Teaching (CLT). In contrast to other language teaching approaches, CLT emphasizes the importance of using an L2 for meaningful communication. CLT includes a spectrum of activities which are based on "interaction between learners" rather than individualistic approaches to learning (Richards, 2006, p. 2). Specific methodological proposals, such as task-based teaching, have been gaining popularity. The intended outcome of these methodologies is meaningful student-student interaction, which research has shown creates learning opportunities and facilitates the second language acquisition process (Long, 1983; Pica, 1992). However, for CLT to be effectively implemented, students need to have WTC.

International posture. International posture, an attitudinal construct suggested by Yashima (2002), may be a specific factor influencing WTC among East Asian students. Yashima described international posture as a positive orientation toward the international community, or an "interest in foreign or international affairs, willingness to go overseas to stay or work, readiness to interact with intercultural partners, and, one hopes, openness or a nonethnocentric attitude toward different cultures" (p. 57). Students who have a more positive orientation toward the international world are more likely to be motivated to use English inside and outside of class. Yashima concluded that "the path from international posture to WTC, although not strong, was significant" (2002, p. 62). Results from a study by Aubrey (2010) also indicated that "students who had an interest in international affairs and intercultural communication tended to participate more in class" (p. 47).

East Asian students' acceptance of CLT. In addition to international posture, the degree to which methodologies associated with CLT are accepted by students is a particularly sensitive variable for EFL students in East Asia. According to Wen and Clement (2003), the Chinese educational culture changes the linguistic, communicative, and social variables that affect students' WTC in a Chinese setting. They argue that feelings of "belongingness," "oneness," and "we-ness," characteristic of in-group members, are essential for successful interaction in the classroom (p. 26). In East Asia, CLT is sometimes considered to diverge from traditional teacher-centered approaches that focus on transmitting information from teacher to student. Audiolingualism, grammar-translation, and situational language teaching are some of the most common methods used in China and Japan (Watkins, 2005). Researchers have argued that CLT may pose a conflict between western educational values and East Asian traditional education (Cortazzi \& Jin, 1996; Hu, 2005) and that the view of language learning as a process rather than learned content causes considerable difficulties (Samimy \& Kobayashi, 2004). However, arguments have been made to the contrary. According to Littlewood (2000), Asian students want to "explore knowledge themselves ... together with their fellow students" (p. 34). Additionally, Aubrey (2010) found that it was not enough for teachers to simply expose students to a communicative learning environment; students needed to exhibit a higher acceptance of CLT in order to be willing to speak in class. In regard to teaching practices for East Asian EFL students, Aubrey (2010) also suggested that "for teachers who want more interaction in their classroom, an attitude shift must take place on the part of students towards a more positive view of CLT and a more "internationally oriented" approach to learning English" (p. 47).

\section{Ways to Increase Student Interaction}

In the following sections, simple suggestions on how to increase interaction in the classroom will be summarized. They are based on classroom implications of past WTC research and are particularly important for teachers seeking ways to manage larger classrooms. Coleman (1989) suggested that the barrier that larger classes have on participation could be overcome by a 
classroom approach that encourages interaction. Aubrey (2010) found empirical evidence to suggest that interaction in larger classes can be increased substantially by focusing on ways to facilitate student-student as opposed to teacher-student interaction. Group cohesiveness, communication anxiety, topic relevancy, acceptance of CLT, and international posture are all factors that can be easily manipulated by teachers to increase students' WTC and studentstudent interaction.

Group cohesiveness. Peer-group cohesiveness may be a unique situation-specific factor influencing East Asian students' WTC in class (Aubrey, 2010; Kim, 2010; Wen \& Clement, 2003). To cultivate cohesiveness, a strong sense of trust between students must be established, to the extent one might find in a family. Some key aspects of attaining this trust are outlined below.

Using positive traits of students. Like a member of a family, a student in a cohesive classroom must learn to value working with their group members more than working individually. Students must come to understand their classmates' positive traits, what they can contribute, and how their individual characteristics can benefit the collective effort. Teachers can promote this process by using some of these simple techniques:

1. Have students explicitly interview each other: "What are your strengths and weaknesses?" "What makes you unique?" "How are you different from others?" etc.

2. Hold elections where students can vote on leadership positions before group tasks are carried out.

3. After the completion of classroom language tasks, such as presentations or groups projects, give students a small amount of time to reflect on how each student contributed and in what aspect each student excelled. This reflection time could take the form of a small group discussion or a written peer evaluation.

4. Keep records of feedback on individual students. If students are comfortable with each other, ask permission from students to display their positive feedback on a wall chart for all students to view. Use this to inform your choice of classroom seating, pairing students, or group project membership.

Facilitating an awareness of individual positive traits acts as a validation process, whereby each student's being part of the "in group" (i.e., class membership) is justified.

Personalizing student connections. Some students may be shy and might not put themselves in a position to get to know every student in the class; therefore, the teacher may want to facilitate connectedness among class members in the ways listed below:

1. Enable student-student networking by compiling a list of student email addresses and handing them out to all students in class. Students could voluntarily submit their emails to the class list if the teacher foresees student privacy problems.

2. Have students organize birthday events, off-campus meetings, or holiday celebrations.

3. Have students rely on each other for task and course information. For example, the teacher could email homework to only half the class; the other half would have to contact their peers in order to obtain the required homework instructions. 
Making student networking a key component of every class will increase group cohesiveness and improve students' WTC.

Communication anxiety. L2 anxiety often stems from a fear of exposure or risk of being judged by peers who may notice imperfections (Aubrey, 2010; De Saint Léger \& Storch, 2009; Donato \& McCormick, 1994; Young, 1990). To lower anxiety and increase students' WTC, teachers may want to limit the amount of forced exposure imparted on a student. Decreasing students' perceived imperfections in language production will most likely increase their WTC. To increase a student's confidence in this way, it is necessary for teachers to adjust their approach in eliciting student participation, as the following suggestions propose:

1. Allow plenty of time for students to prepare an answer. It is tempting to single out students by name and elicit spontaneous responses to questions, but this can be a stressful experience for students.

2. Write questions on the board and divide students into groups to discuss possible answers among themselves. Without forcing students to expose their answers to the whole class, the teacher can walk around, listen to discussions, give positive feedback, and encourage group members to share good answers with the class.

By following these techniques, teachers are both encouraging students to voluntarily participate and eliciting valuable student-student interaction. This results in richer, more accurate student responses.

Topic relevancy. Making the lesson topic interesting and personally relevant to students has been shown to enhance students' WTC (Aubrey, 2010). Students who do not have an interest in the lesson content may not participate. Even if the required curriculum is rigid, there are at least two approaches to increasing topic relevance that can be used to build WTC.

Knowledge of student interests. Knowing the interests of students can be a powerful teaching tool. It makes lessons interesting and can harness a student's latent WTC. Below are some suggestions for achieving this:

1. Administer a short questionnaire that surveys students' hobbies, dreams, goals, and general interests.

2. Adjust how lessons are presented based on this knowledge. Use language in the context of students' interests and prepare debates, tasks, or other activities that will elicit WTC based on topic interest.

3. Incorporate topics into lessons with the purpose of making English immediately useful for students and eliminate, when possible, irrelevant topics. For example, activities could be based on popular American TV shows or movies.

Students are more likely to participate freely in English if they are absorbed in the content.

Giving students some content control. For teachers who have a degree of control over the content of their courses, and to aid the transition to a more learner-centered classroom, having students choose what and how they learn can maximize lesson relevancy. Some possible strategies follow: 
1. Preview textbook chapters or the course curriculum. Have students vote on which parts to omit or include.

2. Give students a choice. Make lists of writing topics, speaking tasks, and authentic listening or readings. Have students choose which they find most stimulating.

3. Be flexible with the skills taught in class. Obtain input from students on how much time should be spent on writing, listening, speaking, or reading.

4. Assign a class leadership position to a different student each week. The student leader can be responsible for making day-to-day content decisions along with the teacher.

Relinquishing complete control may not be wise. Many students may be unaware of what they need to learn, so asking "What do you want to learn today?" may not be a suitable approach. However, by giving students choices, teachers remain in control while letting students begin to more confidently exercise their right to choose what they learn.

Acceptance of CLT. Task-based teaching and other popular pedagogical proposals that fall under the umbrella of CLT are useful in that they promote classroom interaction. However, interaction can only happen if students consider this learning environment beneficial. Past research (Aubrey, 2010; Littlewood, 2000) has indicated that Asian students respond positively to CLT under certain conditions. Of particular interest to teachers is the finding that having a more "positive attitude towards CLT is essential for producing an ideal classroom situation" (Aubrey, 2010, p. 42).

"Selling" CLT. To give students a positive orientation toward the CLT approach, teachers need to try to "sell" their CLT methodology to students from the first day of class. Just as languagelearning researchers need to provide evidence to teachers of how language is acquired (in the form of peer-reviewed journal articles), teachers should articulate their approach in the classroom and show how it is beneficial. Some possible approaches follow:

1. Explicitly communicate to students what CLT is and how it will be used in the classroom.

2. Give examples of CLT-type tasks and activities that will be used in the course.

3. Explain why CLT is being used. Highlight potential benefits.

4. Use simple empirical or anecdotal evidence to support the choice of CLT. For example, show students results of action research or case studies that illustrate how former students showed a positive attitude toward this teaching approach and, as a result, improved their language skills.

5. Emphasize that for CLT to work, there needs to be voluntary student participation.

Teachers can facilitate an attitude change towards a more positive acceptance of CLT by making it clear that participation is a proven path to language learning success and that this is most easily achieved through communicative activities that involve other students.

Instilling an international posture. Maclntyre (2007) states that "the major motivation to learn another language is to develop a communicative relationship with people from another cultural group" (p. 569). Evidence has clearly been provided to support this claim, particularly results which suggest a significant positive correlation between international posture and WTC (Aubrey, 2010; Yashima, 2002, 2004). If students who are more internationally oriented are 
more willing to interact in class using English, then international posture is clearly something EFL teachers need to instill in their students. Some possible approaches follow.

Making use of international students. To interest students in the world of English, one suggestion is to make use of international students at the same institution. The Contact Hypothesis states that there is reduced prejudice and hostility when two segregated groups come into contact with each other (Pettigrew, 2007). In other words, EFL students will take on a more positive attitude toward the international community if they come into regular contact with international students. Teachers can facilitate this by using the techniques below:

1. Have international English-speaking students speak to the class about their home culture.

2. Have students find and interview international students outside of class and use their interview data in class projects.

3. Make use of virtual international communities. Social networking sites, such as Facebook, can provide virtual intercultural interaction, which is especially useful if the local international-student community is limited.

Meaningful exposure to international students is a valuable way of connecting English to the world outside of students' immediate non-English speaking community.

Instilling global awareness. "A global cultural awareness is the missing link connecting basic English competence and fluent intercultural communication" (Aubrey, 2009, p. 130). Teachers can adjust teaching practices in the following ways with the goal of instilling in their students a global awareness:

1. Implicitly incorporate culture into the classroom by carefully selecting texts written by authors from a variety of English-speaking cultures. Moreover, these reading texts can be used by the teacher as segues into critical reading exercises focusing on learning and understanding different cultures.

2. Dispel cultural stereotypes. Nowlan (2009) suggests "having students develop a list of stereotypes one group of people may have of another, then having students identify exceptions and falsehoods of each stereotype" (p. 150).

3. Explicitly incorporate culture by including topics such as nonverbal communication, individualism / collectivism, and high / popular culture into the course.

4. Use current international events as a focus of discussion in class. Political or human-interest news stories can be used in class with other materials or on their own.

Raising the global cultural awareness of students can lead to an increase in international posture, which in turn, may ignite a motivation to speak English.

\section{Conclusion}

Kang (2005, p. 291) points out that teachers should "provide the factors facilitating WTC as much as possible, instead of focusing on one factor at the expense of other facilitating factors." In response to this, this paper has made some suggestions on how to capitalize on some of the most pertinent factors leading to classroom interaction. To conclude, traits of a high-WTC student will be summarized. 
According to past research and in line with the teaching suggestions above, to be a meaningful participant in a large EFL classroom, a student must: (1) be ready to interact with other students, because it is believed that individual linguistic knowledge can be shared and collectivistic knowledge will be increased by doing so; (2) have low anxiety when interacting with peers, either because there is a high level of trust between all students or because the teacher rarely puts the student in a vulnerable position where mistakes are being exposed; (3) find the lesson topic personally relevant and tasks engaging; (4) understand the teacher's classroom philosophy and believe that the ensuing methodology is ultimately beneficial for language learning; and (5) have an interest in international people, travel, and issues, along with a desire to be an active member of the global community. By being mindful of the teaching practices outlined in this paper, teachers can realistically and practically cultivate the above attributes in their students.

\section{Author Note}

Scott Aubrey, Center for Language Education, Ritsumeikan Asia Pacific University, Japan.

Correspondence concerning this article should be addressed to Scott Aubrey. Email: scaubrey@apu.ac.jp 


\section{References}

Aubrey, S. (2009). Creating a global cultural consciousness in a Japanese EFL classroom. CCSE English Language Teaching, 2(2), 119-131.

Aubrey, S. (2010). Influences on Japanese students' willingness to communicate across three different sized EFL classes (Master's thesis). Asian EFL Journal. Retrieved from www.asian-efl-journal.com/Thesis/Thesis-Aubrey.pdf

Cao, Y., \& Philp, J. (2006). Interactional context and willingness to communicate: Comparison of behavior in whole class, group and dyadic interaction. System, 34(4), 480-493. http://dx.doi.org/10.1016/j.system.2006.05.002

Coleman, H. (1989). Approaches to management of large classes. Lancaster-Leed Language Learning in Large Classes Research Project. Report No. 11.

Cortazzi, M., \& Jin, L. (1996). Cultures of learning: Language classrooms in China. In H. Coleman (Ed.), Society and the language classroom (pp. 169-206). Cambridge, England: Cambridge University Press.

Donato, R., \& McCormick, D. (1994). A sociocultural perspective on language learning strategies: The role of mediation. The Modern Language Journal, 78(4), 453-464. http://dx.doi.org/10.2307/328584

Hu, G. W. (2005). Contextual influences on instructional practices: A Chinese case for an ecological approach to ELT. TESOL Quarterly, 39(4), 635-660. http://dx.doi.org/10.2307/3588525

Kang, S. J. (2005). Dynamic emergence of situational willingness to communicate in a second language. System, 33(2), 277-292. http://dx.doi.org/10.1016/j.system.2004.10.004

Kim, Y. Y. (1991). Intercultural communication competence: A systems-theoretic view. In S. Ting-Toomey \& F. Korzenny (Eds.), Cross-cultural interpersonal communication (pp. 259-275). Newbury Park, CA: Sage.

Léger, D., \& Storch, N. (2009). Learners' perceptions and attitudes: Implications for willingness to communicate in an L2 classroom. System, 37(2), 269-285.

http://dx.doi.org/10.1016/j.system.2009.01.001

Littlewood, W. (2000). Do Asian students really want to listen and obey? ELT Journal, 54(1), 31-36. http://dx.doi.org/10.1093/elt/54.1.31

Littlewood, W. (2007). Communicative and task-based language teaching in East Asian classrooms. Language Teaching, 40(3), 243-249.

http://dx.doi.org/10.1017/S0261444807004363

Long, M. (1983). Linguistic and conversational adjustments to non-native speakers. Studies in Second Language Acquisition, 5(2), 177-193. http://dx.doi.org/10.1017/S0272263100004848

MacIntyre, P. D. (2007). Willingness to communicate in the second language: Understanding the decision to speak as a volitional process. The Modern Language Journal, 91(4), 564576. http://dx.doi.org/10.1111/j.1540-4781.2007.00623.x

MacIntyre, P. D., Clément, R., Dörnyei, Z., \& Noels, K. A. (1998). Conceptualizing willingness to communicate in a L2: A situational model of L2 confidence and affiliation. The Modern Language Journal, 82(4), 545-562. http://dx.doi.org/10.2307/330224

McCroskey, J. C., \& Baer, J. E. (1985). Willingness to communicate: The construct and its measurement. Paper presented at the Speech Communication Association Convention, Denver, CO.

Nowlan, A. (2010). Creating a more globally conscious classroom. Language Education in Asia, 1, 147-157. http://dx.doi.org/10.5746/LEiA/10/V1/A13/Nowlan

Pettigrew, F. T. (2008). Future directions for intergroup contact theory and research. International Journal of Intercultural Relations, 32(3), 187-199. http://dx.doi.org/10.1016/j.ijintrel.2007.12.002 
Pica, T. (1992). The textual outcomes of native speaker-non-native speaker negotiation: What do they reveal about second language learning? In C. J. Kramsch \& S. McConnell-Ginet (Eds.), Text and context: Cross-disciplinary perspectives on language study (pp. 198237). Lexington, MA: D. C. Heath.

Richards, J. (2006). Communicative language teaching today. New York, NY: Cambridge University Press.

Samimy, K. K., \& Kobayashi, C. (2004). Toward the development of intercultural communicative competence: Theoretical and pedagogical implications for Japanese English teachers. JALT Journal, 26(2), 245-261.

Watkins, C. (2005). Classrooms as learning communities: What's in it for schools? London, England: Routledge.

Wen, W. P., \& Clément, R. (2003). A Chinese conceptualisation of willingness to communicate in ESL. Language, Culture and Curriculum, 16(1), 18-38. http://dx.doi.org/10.1080/07908310308666654

Yashima, T. (2002). Willingness to communicate in a second language: The Japanese context. The Modern Language Journal, 86(1), 54-66. http://dx.doi.org/10.1111/15404781.00136

Young, D. J. (1990). An investigation of students' perspectives on anxiety and speaking. Foreign Language Annals, 23(6), 539-555. http://dx.doi.org/10.1111/j.19449720.1990.tb00424.x 